\title{
Trabalhonecessário
}

Issn: 1808 - 799X

ano 14, número $24-2016$

\section{POLÍTICAS PÚBLICAS DE QUALIFICAÇÃO, TRABALHO E RENDA NO GOVERNO LULA: UMA ANÁLISE DOS PROGRAMAS VOLTADOS PARA A JUVENTUDE. ${ }^{1}$}

\author{
Jonas Emanuel Pinto Magalhães²
}

\begin{abstract}
Resumo
O artigo aqui apresentado faz um balanço crítico dos programas de qualificação, trabalho e renda e da Política Nacional de Juventude no governo Lula. Traçando o seu histórico, vê-se que o horizonte colocado para a juventude converge para uma perspectiva de adequação ao modelo econômico vigente, em que a garantia do emprego é substituída pela promessa de empregabilidade. Neste contexto, a inserção produtiva dos jovens no mercado de trabalho dependeria da ampliação do seu capital social, do seu empreendedorismo e do investimento nas competências que o mercado valoriza. Por outro lado, reconhece-se que, no governo Lula, inaugura-se um novo marco para as políticas voltadas para a juventude, a partir do surgimento de espaços institucionais em que se fortalece a disputa pela ampliação de direitos para a população jovem, especialmente aquela em maior situação de vulnerabilidade social.
\end{abstract}

Palavras-chave: juventude; desemprego juveniL; protagonismo juvenil; qualificação profissional; Política Nacional de Juventude

\begin{abstract}
The article presented here is a critical assessment of training programs, employment and income and the National Youth Policy under Lula. Charting your history, we see that the horizon placed for youth converges to a perspective of adaptation to the current economic model, where job security is replaced by employability promise. In this context, the productive integration of young people in the labor market would depend on the expansion of its capital, its entrepreneurship and investment in skills valued by the market. On the other hand, it is recognized that in the Lula government, inaugurated a new framework for the policies to youth, from the emergence of institutional spaces that strengthens the competition for expansion of rights for young people, especially that in most situation of social vulnerability.
\end{abstract}

\footnotetext{
${ }^{1}$ Este artigo resulta da pesquisa "Sociabilidade do capitalismo dependente no Brasil e as políticas de formação, emprego e renda - juventude com vida provisória em suspenso", desenvolvida no período de 2008 a 2011. A referida pesquisa contou com financiamento do CNPq e foi coordenada pelo Prof $^{\circ} \mathrm{Dr}^{\circ}$ Gaudêncio Frigotto.

${ }_{2}^{2}$ Mestre formado pelo Programa de Pós-graduação em Políticas Públicas e Formação Humana (PPFH/UERJ). Professor de disciplinas pedagógicas da Rede Estadual de Ensino do Rio de Janeiro. Pedagogo na Faculdade de Educação da Universidade Federal Fluminense.
} 


\section{Trabalhonecessário}

Issn: 1808 - 799X

ano 14, número $24-2016$

Keywords: youth; youth unemployment; youth leadership; professional qualifications; National Youth Policy

\section{Juventude e desemprego}

Nas últimas décadas, o desemprego tem se constituído como um dos mais graves problemas resultantes da nova fase de acumulação do capital. Sob a égide da doutrina neoliberal e com o intenso processo de reestruturação produtiva iniciado em meados da década de 70 , vêm se formando contingentes cada vez maiores de desempregados e de trabalhadores em situação de trabalho precário em todo o mundo. Neste cenário, a juventude tem sido atingida de forma cada vez mais dramática e intensa. No Brasil, estudos de Pochmann (2000, 2004), demonstram que o desemprego juvenil aumentou na década de 90 numa proporção duas vezes maior que o desemprego total. Nesse período, 62,2\% do montante global dos que perderam emprego assalariado estavam entre a população jovem. Assim, o desemprego, consolidado como um problema estrutural já na década de 80 , se intensificou na década de 90 e adentrou o século XXI atingindo de maneira ainda mais significativa a população de 18 a 24 anos:

Em pleno limiar do século 21, a participação relativa do segmento etário de 15 a 24 anos no total da População Economicamente Ativa é de $25 \%$, embora o jovem responda por $50 \%$ do desemprego nacional. Enquanto a taxa de desemprego aberto dos jovens gira em torno dos $18 \%$, a taxa média nacional esteve em $9,4 \%$ do total da força de trabalho, segundo o IBGE (PNAD) no ano de 2001. (POCHMANN, 2004)

Dados apresentados pela Organização Internacional do Trabalho (OIT) em 2009 confirmam que as taxas de desemprego juvenil continuaram em ascensão até 2006, subindo de 11,9\% em 1992 para 18,0\% em 2006, o que representa uma elevação de 51\%. Embora o desemprego também tenha crescido na faixa adulta (5,6\%), ele foi, de fato, 3,2 vezes maior na população mais jovem (17,8\%).

Adotando-se um recorte de classe, com base na renda familiar, veremos 


\section{Trabalhonecessário}

Issn: 1808 - 799X

ano 14, número $24-2016$

que os pobres constituem a parcela da população em estado de maior vulnerabilidade, como deixam entrever esses dados:

Enquanto para os homens de 19 a 24 anos a taxa de desemprego no quintil de renda domiciliar per capita mais elevado era de $7,9 \%$ em 2006, essa taxa crescia para $20,5 \%$ para o quintil de renda mais baixo. A mesma comparação entre as mulheres jovens para a mesma faixa etária apontava resultado similar: um patamar dedesocupação mais elevado para o quintil mais baixo de renda (20\% mais pobres), $34,4 \%$, em comparação com o quintil mais alto de renda ( $20 \%$ mais ricos), que era de $11,3 \%$. (OIT, 2009)

De acordo com o relatório da OIT, entre os jovens, os mais afetados pelo desemprego são os negros e as mulheres, principalmente aqueles que vivem em áreas urbanas, e, em especial, nas regiões metropolitanas. A questão é ainda mais grave se considerarmos a sobreposição formada por esses dois grupos e 0 critério de renda mencionado anteriormente. Vê-se que, no espectro da população jovem, há grupos em situações bastante dramáticas em termos de inserção no mercado de trabalho. Segundo dados do PNAD (2007) citados pelo IPEA (2009), o Brasil possui hoje cerca de 49,8 milhões de jovens, o que corresponde a $26,54 \%$ da população total. Destes, 29,8\%, cujas famílias vivem com renda familiar per capita de até meio salário mínimo, podem ser considerados pobres. Não é um contingente desprezível em face do conjunto da população em geral e dos jovens brasileiros na faixa de 15 a 29 anos.

Além da falta de oportunidade no mercado de trabalho, não menos problemática é a situação educacional desses jovens. Apesar de ter havido um aumento considerável na escolaridade média da população em geral, constata-se que persistem problemas como a elevada distorção idade-série. No ensino médio, por exemplo, apenas 47,9\% dos jovens de 15 a 17 anos cursavam o ensino médio, considerado o nível de ensino adequado a esta faixa etária. A situação é ainda pior na área rural, onde este número não ultrapassava 30,6\% (IPEA, 2009). Para esse jovem, parece haver um momento em que a necessidade de buscar trabalho se impõe como condição de sobrevivência, o que certamente tem impactos negativos na sua trajetória escolar, seja pela elevada jornada de 


\section{Trabalhonecessário}

Issn: 1808 - 799X

ano 14 , número $24-2016$

trabalho que o impede de cursar o ensino médio de maneira adequada ou mesmo o obriga a abandonar os estudos, seja pelas condições precárias de trabalho que também impactam o seu desempenho escolar. Tais situações respondem, em parte, pelos elevados índices de evasão escolar no Brasil e contribuem para que tenhamos hoje 18,4 milhões de jovens fora da escola, ou o correspondente a $53,1 \%$ da população de 18 a 24 anos de idade (OIT, 2009). Pode-se supor que muitos desses jovens voltarão à escola em algum momento da vida, mas certamente o farão construindo itinerários formativos descontínuos, fragmentados e em condições desfavoráveis, motivados por razões de ordem econômica e social.

Num cenário em que os jovens são excluídos do mercado de trabalho pela falta de oportunidades e da escola pela falta de condições de nela se manter, vem crescendo a preocupação de organismos internacionais e dos governos com o grupo de jovens que não estudam nem trabalham, o que os colocam em condições de elevado risco social, ou seja, situações em que a pobreza associada à desigualdade aumentaria a probabilidade de envolvimento com o crime, dependência química, gravidez precoce, etc. Os dados mais recentes da OIT (2009) apontam que existem hoje 18,8\% de jovens nessa situação, excluídos da escola e do trabalho. Mas, segundo a própria OIT, o número de jovens em situação de vulnerabilidade social pode ser ainda maior se incluirmos nesse grupo os jovens empregados na informalidade. Cabe destacar o expressivo aumento da taxa de informalidade verificado no final da década de 90, e que compõe com o desemprego um agravante quadro de exclusão do mercado formal de trabalho:

Dos 22 milhões de jovens economicamente ativos em 2006, aproximadamente 3,9 milhões estavam desempregados e 11 milhões estavam inseridos em ocupações informais. Isto significa que 15 milhões de jovens brasileiros economicamente ativos estavam excluídos de um emprego formal devido ao desemprego ou à informalidade. (OIT, 2009)

Assim, eliminando-se a sobreposição entre empregados na informalidade e desempregados que não estudam, tínhamos, em 2006, 55\% ou 19,3 milhões de 


\section{Trabalhonecessário}

Issn: 1808 - 799X

ano 14, número $24-2016$

jovens de 18 a 24 anos, em situação de vulnerabilidade social. Considerando o aumento da faixa etária compreendida para definição de juventude para 29 anos e a projeção de que em 2010 teríamos 51,3 milhões de pessoas nessa faixa, podemos ter hoje mais de 28 milhões de jovens em situação de vulnerabilidade social.

Foi para esses jovens que se voltaram, prioritariamente, os programas de políticas públicas da juventude no Brasil no governo Lula. Entretanto, realizou-se, naquele período, uma mudança paradigmática que deslocou para os programas de qualificação, geração de trabalho e renda o foco das ações que visavam reduzir a vulnerabilidade dos jovens em situação de risco social.

Com essa mudança, a Política Nacional de Juventude afinou-se com as principais orientações dos organismos internacionais, particularmente a UNESCO, adotando como principal linha de ação a implementação de programas compensatórios que buscavam integrar os jovens à nova sociabilidade do capital. A elevação do nível de escolaridade e a qualificação para o trabalho simples são adotadas como eixos que buscam minimizar os déficits sociais determinados pelos processos de exclusão, cujo principal subproduto tem sido o desemprego. Assim, se até a década de 90 os programas para juventude se voltavam quase que exclusivamente para o controle do tempo livre, e, nesse sentido, estavam sob risco social apenas os jovens "desocupados", posteriormente, o que se observou, segundo Pochmann (2000), foi a ampliação da crise social juvenil estaria agora relacionada aos processos de integração à vida adulta, particularmente, a passagem da escola ao mercado de trabalho.

Essa mudança, que não se processa mais de forma tão linear, confere à juventude uma condição de provisoriedade, como uma etapa inconclusa que vai se postergando na medida em que se afunila o gargalo do mercado de carreiras estáveis. Não por acaso, a atual Política Nacional de Juventude ampliou para até 29 anos a faixa de atendimento de alguns programas para jovens. Não se trata obviamente de uma revisão epistemológica do conceito de juventude, mas de uma medida pragmática que reconhece, mais do que a postergação da condição da juventude, a crise compreendida pelos problemas de integração à vida adulta, 


\section{Trabalhonecessário}

Issn: 1808 - 799X

ano 14 , número $24-2016$

particularmente no que se refere à inserção do jovem no mercado formal de trabalho.

É a partir desse panorama que analisaremos, a seguir, os principais programas dirigidos aos jovens, nos oito anos de governo Lula, procurando compreendê-los não apenas sob o prisma ideológico, mas também do ponto de vista de sua efetividade social.

A despeito das diferentes orientações que permeiam o debate e da maior ênfase dada ao tema da participação juvenil nos últimos anos, estamos inclinados a aceitar a hipótese de que as políticas de Juventude do governo Lula amparadas ideologicamente pelas noções de protagonismo juvenil, empregabilidade e participação cidadã se configuraram como um novo mecanismo de controle do "risco social" e de conformação da juventude ao modelo de desenvolvimento econômico subordinado aos grandes centros hegemônicos do capitalismo mundial. Este esgotando sua dimensão civilizatória, coloca como condição de sua sobrevivência o gerenciamento da pobreza.

Por outro lado, a Política Nacional de Juventude constituiu um marco importante no qual o Estado reconhece a população jovem como sujeito de direitos que merecem um tratamento diferenciado nas políticas públicas, adotando um modelo que, do ponto de vista formal, supera a visão "pessimista" da juventude e prevê ações e programas voltados para direitos básicos como a educação e o emprego.

O caminho percorrido até a consolidação desse modelo foi marcado por conflitos e contradições, protaganizados pelo embate das forças políticas que representam os três projetos de desenvolvimento ${ }^{3}$, que segundo Frigotto (2005), compuseram o arco de alianças de matriz ideológica eclética que elegeram o presidente Lula. As políticas de juventude, como não poderia ser diferente, se moveram no plano de disputas desses grupos.

\footnotetext{
${ }^{3}$ Citando Fiori (2002), Frigotto (2005) apresenta sinteticamente essa matriz composta por: 1) o projeto assentado nas teses do liberalismo econômico e centrado no ajuste fiscal, o projeto do nacionalismo conservador e de cunho populista típico da era Vargas e o projeto de desenvolvimento econômico nacional e popular.
} 


\section{Trabalhonecessário}

Issn: 1808 - 799X

ano 14 , número $24-2016$

Assim, é possível estabelecermos algumas relações entre as políticas para a juventude, as políticas de formação profissional e o projeto de desenvolvimento econômico privilegiado nesse período.

\section{Programas de qualificação profissional, trabalho e renda no governo Lula: a juventude em foco.}

Kuenzer (2006), em artigo que trata das políticas de Educação Profissional do Governo Lula, identifica, a partir do Programa Nacional de Qualificação (PNQ), três linhas programáticas que operacionalizaram as políticas de Educação Profissional no governo Lula. A primeira, constituída de ações baseadas na reformulação do PLANFOR; a segunda, que articula-se diretamente à Educação Básica, realiza-se como continuidade ao PRONERA e PROEP revitalizando-se através da criação do PROJOVEM e do PROEJA; e a terceira, dirigida mais diretamente aos jovens em situação de vulnerabilidade social, tendo como carrochefe o Programa Nacional do Primeiro Emprego (PNPE). Como veremos, ao longo dos oito anos do Governo Lula, a primeira e a terceira linhas foram suprimidas pela segunda, que tem como marca a articulação entre a formação profissional e a elevação da escolaridade e mantém o foco nos jovens em situação de vulnerabilidade social, embora apresente-se, dentro da visão "otimista" da juventude, como projeto que aposta no protagonismo juvenil.

No estudo que realizamos, identificamos três períodos que expressam bem "para que lado a balança vai pendendo" nessa correlação de forças e o que eles representaram em termos de avanços e retrocessos para o projeto de "desenvolvimento econômico nacional e popular", com o qual nos identificamos.

Para melhor compreendermos esse movimento e a consolidação, ao longo dos oito anos do governo Lula, da política de juventude, faremos uma rápida caracterização desses períodos, para, em seguida, analisar as matizes ideológicas presentes nos principais programas de políticas para juventude, seu efetivo impacto e a lógica que as orientam . 


\section{Trabalhonecessário}

Issn: 1808 - 799X

ano 14 , número $24-2016$

Período de 2003 a 2005 - Entre a continuidade da política de profissionalização restrita e os primeiros ensaios de uma política "original" com ênfase na demanda.

$\mathrm{Na}$ ausência de referências normativas que orientassem a formulação de políticas para a juventude, o governo pareceu ter optado por reformular os programas de qualificação, herdados do governo de Fernando Henrique Cardoso, mantendo a descentralização, a focalização e a "terceirização" da execução dos programas. O Plano Nacional de Qualificação Profissional (PLANFOR) foi substituído em 2003 pelo Plano Nacional de Qualificação (PNQ), mantendo basicamente as mesmas características, inclusive com repasses à iniciativa privada e ao terceiro setor. O Programa Escola de Fábrica orientou-se pela mesma lógica, diferenciando-se basicamente pelo fato de se dirigir ao público mais jovem. Tendo suas origens no projeto Formare, da Fundação Lochpe,criado em 1998, o programa Escola de Fábrica se apoiou nas parcerias estabelecidas com empresas e indústrias responsáveis pela qualificação profissional de jovens e por seu possível aproveitamento. Cabe destacar que a revogação do Decreto $\mathrm{n}$. 2.208/97, compromisso assumido pelo presidente com os educadores progressistas e que poderia acenar para uma possível integração entre o ensino profissional e ensino básico, não surtiu os efeitos esperados, e o que se constatou em relação aos programas de formação profissional mencionados foi a adoção de um modelo restrito à aprendizagem profissional.

O fato é que, após um ano de vigência do Decreto n. 5.154/2004, a mobilização esperada não ocorreu. O que se viu, logo a seguir, foi o inverso. De uma política consistente de integração entre educação básica e profissional, articulando-se os sistemas de ensino federal e estaduais, passou-se à fragmentação iniciada internamente, no próprio Ministério da Educação (CIAVATA, FRIGOTTO e RAMOS, 2005)

O Programa Nacional do Primeiro Emprego (PNPE), criado em 2003, institui o marco inicial das políticas de qualificação, trabalho e renda dirigidas especificamente para jovens. Atuando em diversas linhas nas quais se destacam: 


\title{
Trabalhonecessário
}

Issn: 1808 - 799X

ano 14 , número $24-2016$

os incentivos à contratação de jovens sem experiência pregressa, empreededorismo e qualificação profissional através de consórcios sociais da juventude, o programa não logrou sucesso naquilo que era seu mote principal: a indução da demanda. O PNPE passou então a focar ações de qualificação por meio dos consórcios sociais da Juventude e os parcos resultados obtidos em sua principal linha de ação serviram de justificativa para a reorientação da política de qualificação, trabalho e renda dos jovens:

\begin{abstract}
Apesar das mudanças efetuadas em 2004, a ação de subvenção permaneceu com baixo patamar de execução até 2007, quando foi encerrada. A fraca execução dessa linha foi fundamental para explicar a reestruturação das políticas voltadas para a juventude, promovidas pelo governo federal em 2005, o que significou uma mudança de ênfase das ações do lado da demanda para ações do lado da oferta no mercado de trabalho, em especial aquelas direcionadas à elevação profissional (OIT, 2009).
\end{abstract}

De acordo com Sposito (2005), inicia-se, em 2004, um amplo processo de diálogo entre governo e movimentos sociais com o intuito de se instalar uma política de juventude no país, que concede projeção nacional à temática da juventude. O desafio era, de acordo com a autora, o de pensar políticas que, por um lado, visassem à garantia de cobertura em relação às diversas situações de vulnerabilidade e risco social apresentadas para os jovens e, por outro, buscassem oferecer oportunidades de experimentação e inserção social múltiplas, que favorecessem a integração dos jovens nas várias esferas sociais.

Constituiu-se, então, o Grupo Interministerial da Juventude, envolvendo 19 Ministérios, Secretarias e órgãos técnicos especializados, para elaborar um diagnóstico sobre a juventude brasileira e realizar um levantamento das ações governamentais que eram dirigidas especificamente aos jovens ou contemplassem segmentos juvenis. Esperava-se que servissem de referências para elaboração de diretrizes para uma política nacional de juventude.

Técnicos do Instituto de Pesquisa Econômica Aplicada (IPEA) colaboraram nesta tarefa produzindo informações estatísticas pertinentes. Também foram incorporados resultados de pesquisas e consultas realizadas pela UNESCO e 


\section{Trabalhonecessário}

Issn: 1808 - 799X

ano 14, número $24-2016$

pelo Projeto Juventude do Instituto Cidadania ${ }^{4}$, participante do trabalho de acompanhamento e estudos de propostas de Políticas Públicas para a Juventude realizada pela Comissão Especial da Câmara dos Deputados.

\section{Período de 2005 a 2007 - Estabelecimento do Marco Referencial para a Política de Juventude e a mudança para "indução" da oferta.}

Os trabalhos e debates promovidos pelo Grupo Interministerial da juventude culminaram na assinatura em, $1^{\circ}$ de fevereiro de 2005, pelo Presidente da República, de uma medida provisória que instituiu a Política Nacional da Juventude. Nesse mesmo ato, foram criados o Programa Nacional de Inclusão de Jovens (PROJOVEM), a Secretaria Nacional de Juventude (SNJ) e o Conselho Nacional de Juventude (CONJUVE).

Inegavelmente trata-se de um importante marco. Criaram-se novas possibilidades de participação política dos jovens, e, consequentemente ampliaram-se a interlocução e o diálogo intergeracional, o que, por sua vez, contribuiu para desconstrução de representações simplificadoras das juventudes. Ao mesmo tempo, reconheceu a juventude como portadora de direitos, ainda que nem sempre se reconheça a universalidade desses direitos.

Contudo, cabe questionar através quais segmentos tiveram seus interesses representados nos diferentes projetos de desenvolvimento e qual o peso que tiveram na construção de uma agenda única para a juventude.

Os princípios que orientaram as ações e os programas desenvolvidos a partir deste novo marco nos permitem concluir que a "balança" mais uma vez pendeu para o lado dos interesses do grande capital, que tiveram na voz da UNESCO e do Instituto Cidadania seus interlocutores mais diretos. Nas

${ }^{4}$ O Instituto Cidadania, atualmente denominado Instituto da Cidadania do Brasil, é uma Organização da Sociedade Civil de Interesse Público (OSCIP) que tem entre seus parceiros as secretarias de educação e de cultura do Estado de São Paulo, a secretaria de educação da prefeitura da cidade de São Paulo, A Fiesp, o Sebrae-SP e o instituto Volkswagem. Na sua página eletrônica coloca como missão "difundir os conceitos de cidadania em todos os segmentos que formam a nação brasileira e defender que todo cidadão tenha seus direitos e obrigações aplicados no seu dia a dia." 


\section{Trabalhonecessário}

Issn: 1808 - 799X

ano 14, número $24-2016$

orientações de ambos há indicações muito claras para que o Estado institua políticas focalizadas que promovam a formação profissional em cursos relativamente breves, dirigidos aos segmentos mais pobres, mormente, aquele grupo mais vulnerável, em situação de "risco social", ou seja, o de jovens que não estudam nem trabalham.

Não obstante, também havia indicações para que a Política Nacional de Juventude promovesse ações voltadas para o protagonismo juvenil, o que na prática significaria o estímulo ao empreendedorismo, à participação cidadã por meio de ações comunitárias e do trabalho voluntário e à ampliação do capital social, visto como importante elemento para a empregabilidade. De fato, as diretrizes traçadas pela UNESCO se materializaram com a criação do PROJOVEM, que, longe de ser um programa desenhado a partir de uma "ampla discussão com a sociedade", copia um modelo inaugurado pelo Governo Chileno na metade da década de 90. Copiar, nesse caso, não é apenas uma expressão que denota adesão a princípios, pois, de fato, até mesmo o nome do programa não é algo original, mas tomado de empréstimo de experiências comuns desenvolvidas em países da América do Sul:

Contando com a mesma denominação (PROJOVEN), os programas de capacitação para o trabalho do Peru e do Uruguai foram capazes de criar uma fecunda experiência, causando um impacto importante em termos da empregabilidade dos jovens. Trata-se de dois programas construídos seguindo a lógica do Programa Chile Joven, postos em prática em meados da década de 90 , tendo como alvo os jovens menos privilegiados - que, em geral, abandonaram o sistema educacional e que estavam sem trabalho no momento em que ingressaram no programa - e que atuam em torno de postos de trabalho realmente existentes, formulando respostas de capacitação para o trabalho e para a atividade empresarial, específica para cada contexto particular. (UNESCO, 2004)

A julgar pelos rumos que a Política Nacional de Juventude tomou desde então, o pretenso debate com a sociedade, que deveria ter sido conduzido pelo Grupo Interministerial da Juventude, parece ter servido também para referendar orientações vindas de organismos internacionais, já que ações importantes como 


\section{Trabalhonecessário}

Issn: 1808 - 799X

ano 14, número $24-2016$

a criação da Secretaria Nacional de Juventude (SNJ) e o Conselho Nacional de Juventude (CONJUVE) atendiam as formulações elaboradas pela UNESCO.

A partir de então, a Política Nacional da Juventude assume como principal linha de ação os programas emergenciais focados na parcela da população jovem de maior vulnerabilidade, ou seja, a juventude pobre e trabalhadora. Porém, a estratégia agora inclui também ações em que o jovem é chamado a contribuir com o seu protagonismo, seja através de sua participação "cidadã", seja através do investimento em sua empregabilidade, pela elevação da sua escolaridade e pela qualificação.

\section{Período de 2007 - 2010 - Consolidação do Projovem como programa de referência e a afirmação das políticas focais como principal orientação da Política Nacional de Juventude}

Dois anos após ter sido criada a Política Nacional de Juventude, permanecia como problema a pouca articulação e integração entre os principais programas, o que colocava a necessidade de se rever o desenho e a coordenação desses programas. Naquele momento, através de cinco ministérios diferentes, o governo federal executava seis programas emergenciais voltados para a juventude de baixa escolaridade e reduzida capacitação profissional: ProJovem - Secretaria-Geral da Presidência da República/Secretaria Nacional de Juventude; Consórcio Social da Juventude e Juventude Cidadã - ambos do Ministério do Trabalho e Emprego (MTE); Agente Jovem - Ministério do Desenvolvimento Social e Combate à Fome (MDS); Escola de Fábrica Ministério da Educação (MEC); e Saberes da Terra - Ministério da Educação e Ministério do Desenvolvimento Agrário (MDA).

De acordo com Silva e Andrade (2009), embora esses programas tivessem em comum o mesmo público alvo e operassem na mesma linha - ampliação da escolaridade e formação profissional com repasse de diferentes auxílios financeiros aos jovens, como contrapartida de sua participação nas atividades oferecidas - sua gestão e sua execução não se davam de modo integrado, 


\section{Trabalhonecessário}

Issn: 1808 - 799X

ano 14 , número $24-2016$

havendo pouca coordenação entre os programas. Isso comprometia o atendimento a um maior número de jovens excluídos. Todavia, as extinções, fusões ou readequações recomendadas esbarravam na resistência dos órgãos executores dos diferentes programas, que, pelo forte apego institucional, competiam entre si pela marca de programas próprios e pelas diferentes formas de atuação e gestão.

No embate estabelecido, a opção adotada foi manter todos os programas e ações citados abrigados sob o mesmo "guarda-chuva", conferindo uma aparente integração. Assim, o novo Projovem ou ProJovem Integrado resultou da unificação de seis programas já existentes - ProJovem, Agente Jovem, Saberes da Terra, Escola de Fábrica, Consórcio Social da Juventude e Juventude Cidadã - e foi subdividido em quatro modalidades: i) ProJovem Urbano - serviço socioeducativo; ii) ProJovem Trabalhador; iii) ProJovem Adolescente; e iv) ProJovem Campo - Saberes da Terra. Destinado a jovens de 15 a 29 anos, o ProJovem Integrado entrou em vigor a partir de 10 de janeiro de $2008 \mathrm{com}$ o objetivo de oferecer ao jovem sua reintegração ao processo educacional, qualificação profissional e acesso a ações de cidadania, esporte, cultura e lazer. A gestão do programa foi compartilhada entre a Secretaria-Geral da Presidência da República - por meio da Secretaria Nacional de Juventude -, o MTE, o MDS e o MEC.

Apesar da nova configuração, permaneceram problemas antigos como a fragmentação e a superposição de programas e a ausência de unidade entre os mecanismos de decisão, formulação e implementação das políticas.

\section{A marca das orientações dos organismos internacionais na política nacional de juventude}

O desenho da Política Nacional de Juventude foi sendo redefinido e reconstruído ao longo dos oito anos do governo Lula, a partir da supressão e da incorporação de programas dispersos em vários ministérios e com focos diferenciados, a uma linha bem definida de ação cuja expressão máxima pode ser encontrada no Programa Nacional de Inclusão de Jovens (PROJOVEM) em sua 


\section{Trabalhonecessário}

Issn: 1808 - 799X

ano 14, número $24-2016$

mais atualizada e diversificada versão. Ainda que se verifique a superposição de alguns programas e uma falta de organicidade entre os mecanismos de gestão e implementação, é possível afirmar que a Política Nacional de Juventude tinha como linha mestra ações que visavam os jovens em situação de risco social numa perspectiva de acesso a uma cidadania restrita. A qualificação para o trabalho simples, a formação aligeirada e de pouca qualidade e o estímulo à participação cidadã, entendida como ação comunitária e voluntarismo, constituem o seu tripé fundamental. Sob o pretexto de promover o protagonismo juvenil, vê-se que há uma tendência na Política Nacional de Juventude de, ignorando os conflitos de classe gerados pelo modelo econômico vigente, conformar a juventude a uma sociedade de classes excludente, que tem como uma de suas principais marcas o desemprego e a precarização das relações de trabalho.

Atuando como porta-vozes dos centros hegemônicos do capital, organismos internacionais como a ONU, a UNESCO e a CEPAL procuraram disseminar em países periféricos e de capitalismo dependente uma visão idealizada e ideologizada do jovem enquanto ator estratégico do desenvolvimento, a quem caberia o papel de protagonista numa sociedade marcada pela inovação e pelas constantes e aceleradas mudanças tecnológicas. Assim, numa recente publicação da UNESCO, justifica-se a participação dos jovens como sujeitos de direitos e atores estratégicos do desenvolvimento:

[...] por que os jovens? Porque, além do direito ao desenvolvimento de um capital cultural e social, eles e elas podem ser e estar mais preparados do que muitos adultos para lidar com as novas tecnologias, porque não estão ligados a compromissos e interesses sobre a reprodução do status quo, e porque muitos estão dispostos a trabalhar pela transformação das "regras do jogo" que não os contemplam adequadamente e que, portanto, não os apóiam. Definitivamente, porque muitos deles são portadores de uma perspectiva diferente, e têm um compromisso com a justiça, a paz, a democracia e a liberdade. (UNESCO, 2004)

Afirmações dessa natureza carecem de um maior embasamento, e parecem ideologicamente orientadas por uma visão pueril, descontextualizada e 


\section{Trabalhonecessário}

Issn: 1808 - 799X

ano 14, número $24-2016$

elitizada de juventude. Conquanto não expresse a complexidade e a diversidade da condição juvenil, ganha força como constructo ideológico que, a despeito dos recortes de classe, deixa entrever a ideia de que o potencial do desenvolvimento econômico e social de um país tem nos jovens um elemento catalisador. Esse discurso, propalado em forma de apelo social, teve forte penetração nos países da América Latina nos anos 90 e tem tido influência significativa na história recente da política para juventude no Brasil.

Assim é que muitas das orientações contidas no relatório da Unesco (Políticas Públicas de/para/com Juventudes) foram adotadas no momento em que se estabeleceu um marco referencial para Política Nacional de Juventude. Esse processo, antecedido pela criação do Grupo de Trabalho Interministerial de Políticas para a Juventude e pela Comissão Especial sobre Políticas para Juventude da Câmara dos Deputados, contou também com assessoramento técnico do Instituto de Pesquisa Econômica Aplicada (IPEA), com a participação ativa do Instituto Cidadania, ONG dedicada à geração de propostas de políticas públicas que elaborou o documento intitulado "Projeto Juventude" e com a colaboração da UNESCO. Esta, inclusive, acompanhou viagens de estudo a países europeus de integrantes da citada Comissão.

As recomendações contidas nos documentos elaborados pela UNESCO e pelo Instituto Cidadania serviram de base para a criação em 2005, da Política Nacional da Juventude, que teve como importantes marcos a criação da Secretaria Nacional da Juventude (SNJ) e da CONJUVE (Conselho Nacional da Juventude). Porém, foi a partir do redirecionamento do Programa Nacional de Estímulo ao Primeiro Emprego (PNPE) e da criação do Programa Nacional de Inclusão de Jovens (PROJOVEM) que se consolidaram as ações mais afinadas com as orientações prescritas, mormente, pela UNESCO.

No caso do PNPE, o que se verificou foi o deslocamento das ações antes voltadas prioritariamente para subvenção às empresas (no sentido de fomentar a contratação de jovens sem experiência) para ações de qualificação profissional e participação cidadã de grupos em situação de vulnerabilidade social. Esse redirecionamento se deu pela transferência de recursos para ONGs, através de 


\section{Trabalhonecessário}

Issn: 1808 - 799X

ano 14, número $24-2016$

conglomerados chamados de Consórcios da Juventude, que ficaram responsáveis pela qualificação social e profissional e pela inserção de uma porcentagem dos egressos dos cursos no mercado de trabalho ou em formas alternativas de geração de emprego e renda. O pressuposto, endossado nos documentos da UNESCO e do Instituto Cidadania, é que as Organizações da Sociedade Civil possuem experiência acumulada na atuação com jovens quilombolas, indígenas, portadores de necessidades especiais, marginalizados, ou em conflito com a lei, estando, portanto, em condições de alcançar esses jovens que, por sua condição socioeconômica, têm dificuldade de acessar o Sistema Nacional de Emprego (Sine).

No caso do PROJOVEM, o programa aparece claramente referenciado no documento da UNESCO que recomenda ações que conjuguem concessão de bolsas, elevação da escolaridade, qualificação profissional e participação cidadã e devem ser dirigidos aos jovens em condição de risco social. Há inclusive um capítulo dedicado às "experiências bem-sucedidas na América Latina" em que programas, nos mesmos moldes como o "CHILE JOVEN" e "PROJOVEN" (implementados no Uruguai e no Peru) são ressaltados como modelos de políticas de inserção social.

Há de se ressaltar que, mesmo antes do PROJOVEM, já havia previsão de aplicação de recursos em ações voltadas para qualificação profissional, projetos juvenis e concessão de bolsas, mas estas estavam colocadas no contexto da Educação Básica, particularmente o Ensino Médio. Assim, no Plano Pluri Anual 2004-2007 verifica-se a previsão de recursos da ordem de $\mathrm{R} \$ 1.547$ bilhões para o programa Escola Básica Ideal (UNESCO, 2004). É interessante notar que este valor é aproximadamente cinco vezes maior que os $R \$ 300$ milhões garantidos pelo orçamento geral da União em 2005 para a execução do PROJOVEM. Infelizmente, faltam dados que nos ajudem a confirmar se os recursos previstos para a "Escola Básica Ideal" tiveram como destinatários os jovens do ensino médio (o programa previa concessão de bolsas de $R \$ 100,00$ ) ou se o governo optou posteriormente pelo PROJOVEM como forma de focalizar um grupo mais específico. 


\section{Trabalhonecessário}

Issn: 1808 - 799X

ano 14 , número $24-2016$

O fato é que de uma forma ou de outra não só os programas PROJOVEM e PNPE se conformam bem às orientações contidas nos documentos citados, como estão alicerçados em construtos ideológicos reiterados pelos organismos internacionais, com especial destaque para a noção de capital social, competências, protagonismo juvenil, ação comunitária, responsabilidade social e participação cidadã.

O chamado protagonismo juvenil relaciona-se diretamente com a noção de capital humano e se configura enquanto noção orientadora das políticas para a juventude, tal como a ideia de estado de vulnerabilidade social.

A forma como o protagonismo deve ser fomentado passa, segundo o relatório, pela ampliação das competências e habilidades pessoais, pela ação comunitária e participação cidadã e ainda pela ampliação do capital social.

As habilidades pessoais se definem a partir dos quatro pilares da educação elencados pelo relatório para a UNESCO da Comissão Internacional sobre Educação para o Século XXI (DELORS, 1999):

1) habilidades sociais e interpessoais, incluindo comunicação, habilidades de recusa, agressividade e empatia; 2) habilidades cognitivas, incluindo tomada de decisões, pensamento crítico e autocrítica; 3) habilidades para controlar emoções, incluindo o stress e o aumento interno de um centro de controle. (UNESCO, 2004)

Descritas como habilidades para a vida, expressam um perfil de conformação e adequação psicofísica exigido pela nova sociabilidade do capital. Em nossas pesquisas, temos verificado que essas habilidades têm sido enfocadas direta ou indiretamente nos cursos do PROJOVEM e nos cursos de qualificação social promovidos pelos Consórcios da Juventude. Nestes últimos, por terem como sujeitos grupos mais vulneráveis, constata-se uma ênfase maior em aspectos comportamentais (como se vestir e se portar numa entrevista, ser mais tolerante, compreensivo, etc..), insuficientes para promover uma maior inserção laboral mas que parecem contribuir para ampliação e melhoria do convívio social dos jovens em suas comunidades. Vemos, pois, que uma das 


\section{Trabalhonecessário}

Issn: 1808 - 799X

ano 14, número $24-2016$

linhas de ação desses consórcios apontam para a minimização dos conflitos de classe e para a conformação de sujeitos a um contexto social-econômico excludente. Tendo como pano de fundo a desigualdade, essa linha de ação procura também promover o resgate da autoestima e frear o aumento da violência urbana.

Nesse caso, uma das alternativas mais eficazes encontradas pelo Estado para conter a violência seria retirar os jovens da situação de vulnerabilidade social. Essa condição de vulnerabilidade social é caracterizada pela situação de exclusão dos jovens da escola e do mundo do trabalho. Segundo dados do PNAD, em 2005, 22\% dos jovens de 18 a 24 anos não trabalhavam, nem estudavam, estando incluídos, portanto, no grupo de maior risco social.

Este tem sido o público prioritariamente privilegiado em programas como o PROJOVEM, o PNPE e o PROEJA (Programa Nacional de Integração da Educação Profissional com a Educação Básica na Modalidade de Educação Jovens e Adultos). É interessante notar que o PROUNI, embora não seja declaradamente um programa dirigido exclusivamente ao público jovem (assim como o PROEJA), tem atingido majoritariamente os jovens egressos do Ensino Médio, tomando inclusive as notas do ENEM como critério de elegibilidade. Apesar disso, não encontramos referências a este programa na bibliografia consultada sobre as políticas públicas para a juventude no governo Lula. Interpretamos essa ausência como mais uma demonstração de que as "políticas para a juventude" têm sido entendidas como "políticas para jovens em situação de risco social" com um direcionamento bem específico (jovens negros das periferias das grandes metrópoles, fora do mercado de trabalho e da escola), no qual o público atingido pelo PROUNI não se enquadra. Outras pesquisas apontam para essa mesma compreensão.

Em seu estudo, Silva e Silva (2011) identificaram 20 programas nacionais de juventude categorizados por elas como universais, atrativo e exclusivos. Entretanto, segundo as autoras, se adotássemos o recorte de faixa etária acima de 18 anos, esse número cairia, justamente pela ausência de programas destinados especificamente à população jovem que se encontra na faixa mais 


\section{Trabalhonecessário}

Issn: 1808 - 799X

ano 14, número $24-2016$

avançada. Há de se considerar que se trata de um segmento em que a inserção no mercado de trabalho se apresenta como problema de maior preemência, o que não isenta o Estado de prover também para este grupo programas de cunho social, cultural e educativo.

Não deixa de ser significativo que a maior parte dos programas para a juventude esteja voltada para o aumento da escolaridade e esteja sendo executada por instituições educacionais. No levantamento realizado por Silva e Silva, constata-se a baixa oferta de programas na área de cultura, esporte e meio ambiente, enquanto as ações voltadas para o fortalecimento da participação e da cidadania, em maior número, encontram-se vinculadas a programas de elevação da escolaridade.

No caso de políticas como o PROJOVEM e o PROEJA, ficou clara a opção do governo Lula em articular a formação para o trabalho e para cidadania com a elevação da escolaridade, abandonando a política de estímulo ao emprego iniciada com o PNPE e optando por "garantir" maior nível de "empregabilidade" aos jovens.

Permanece o paradoxo: como reduzir a vulnerabilidade social dos jovens em situação de risco se ela tem como principal determinação a exclusão do sistema formal de emprego? A solução sugerida para uma sociedade em que o direito ao emprego ainda não está garantido limita-se então, por um lado, à promessa de empregabilidade, mesmo que à custa de uma formação aligeirada e de uma duvidosa qualificação profissional, e, por outro, à tentativa de conformar os jovens à sociabilidade exigida pelo capital, minimizando os possíveis focos de conflitos através da promoção de uma cultura de paz e de ações como a atuação comunitária, o trabalho voluntário e a participação cidadã (nos limites de uma cidadania restrita).

Para além dos paradoxos e contradições ideológicas que perpassam os programas e políticas públicas voltados para a juventude, é preciso reconhecer que eles se gestam e se desenvolvem em quadro político de maior reconhecimento dos jovens como sujeitos de direitos. Contudo, o equacionamento das demandas e necessidades da juventude deve levar em conta a condição 


\section{Trabalhonecessário}

Issn: 1808 - 799X

ano 14, número $24-2016$

social, econômica e regional dos distintos segmentos tratados como jovens. No caso específico da juventude brasileira, as autoras supracitadas chamam a atenção para a necessidade de ampliação das políticas dirigidas especificamente aos jovens-jovens e jovens adultos.

\section{A prevalência do discurso (e das demandas) do mercado na conformação dos jovens trabalhadores}

Ao adotar a perspectiva proposta pelos Organismos Internacionais, mormente a UNESCO, o Estado tem endossado uma orientação ideológica na qual problemas de ordem macrossocial e econômica, como o desemprego e a educação, têm sua responsabilidade transferida da esfera pública para a esfera privada, ou ainda, para a esfera individual. Isso não significa que o Estado esteja completamente ausente ou que tenha saído de cena, mas a sua atuação está orientada para incluir os segmentos que se encontram à margem das esferas de produção e consumo, ainda que muitos permaneçam excluídos da esfera dos direitos. Caberia então ao Estado "corrigir" distorções que escaparam da mão invisível do mercado, recolocando nos trilhos os vagões que seguirão no trem do desenvolvimento. Nessa perspectiva compensatória, conforme afirma Ramonet (1998, p.60): "Os poderes públicos não passam, na melhor das hipóteses, de terceirizadores da empresa. O mercado governa. O governo gere". Os jovens são instados a condição de permanente competição, na qual os discursos apologéticos em favor de um cultura solidária, do voluntariado e da ação comunitária se orientam apenas para os interesses mais imediatos da sobrevivência e dissimulam o verdadeiro caráter das políticas focais: a negação do direito ao emprego e à educação de qualidade, num processo que Kuenzer prefere chamar de inclusão excludente: 
Issn: 1808 - 799X

ano 14 , número $24-2016$

Já do ponto de vista da educação, estabelece-se um movimento contrário, dialeticamente integrado ao primeiro: por força de políticas públicas "professadas" na direção da democratização, aumenta a inclusão em todos os pontos da cadeia, mas precarizam-se os processos educativos, que resultam em mera oportunidade de certificação, os quais não asseguram nem inclusão, nem permanência. Em resumo, do lado do mercado, um processo de exclusão includente, que tem garantido diferenciais de competitividade para os setores reestruturados por meio da combinação entre integração produtiva, investimento em tecnologia intensiva de capital e de gestão e consumo precarizado da força de trabalho. Do lado do sistema educacional e de Educação Profissional, um processo de inclusão que, dada a sua desqualificação, é excludente. (KUENZER, 2006).

A face mais perversa desse duplo processo se revela subjetivamente e objetivamente na situação de provisoriedade, nas aflições, e, principalmente nos medos dos jovens de não corresponderem às expectativas que a sociedade, a família e a que eles próprios se colocam em relação a sua posição social, seu emprego, suas necessidades de sobrevivência e suas aspirações de vida.

A juventude brasileira tem se defrontado cada vez mais cedo com a necessidade de fazer escolhas. Escolhas difíceis que vão desde a opção por trabalhar, estudar ou conciliar as duas atividades, até a definição da carreira profissional que deverão seguir. Escolhas que são cada vez mais orientadas por questões de sobrevivência e perspectivas de inserção no mercado de trabalho do que por projetos pessoais. Escolhas que as condições de classe vão transmutando em imposições e que dizem respeito a uma sociabilidade que tem no mercado a sua principal referência.

Revitalizada por novos constructos ideológicos, a Teoria do Capital Humano se mostra presente na disseminação dessa nova sociabilidade que exige não só competências profissionais básicas, mas também as competências sócio emocionais, numa espécie de conformação ideológica na qual a própria subjetividade humana é encarada como fator de produção. O discurso produzido pelas agências internacionais e por seus intelectuais orgânicos que coloca o jovem na condição de protagonista do desenvolvimento, responsabilando-o por sua empregabilidade, na busca por desenvolver atitudes e competências que o permitam competir no mercado. 


\section{Trabalhonecessário}

Issn: 1808 - 799X

ano 14 , número $24-2016$

Num recente artigo publicado pela revista Onda Jovem, produzida pelo Instituto Votorantim e direcionada ao público juvenil, José Pastore, importante economista brasileiro, dita em tom imperativo algumas dessas atitudes que o jovem deve adotar para se adequar às exigências do mercado. Embora longo, permito-me citar o trecho que expressa de modo emblemático como esse discurso tem chegado aos jovens.

O mercado de trabalho está se tornando cada vez mais exigente. As empresas não contratam diplomas, currículos ou recomendações. O tempo do pistolão e do apadrinhamento acabou. As empresas querem respostas, por isso contratam profissionais curiosos, com capacidade de apreender continuamente. Daí a importância da boa formação.Você que é jovem, leve isso em conta. Quando o professor pedir para ler um livro, leia dois. Quando pedir dois, leia quatro. Crie o hábito de estudar por conta própria. Aproveite todos os momentos de folga para aprender, aprender e aprender. Se o emprego está difícil para quem estuda, imagine as dificuldades para quem vive nas trevas. Portanto, defina sua meta e procure ficar sempre acima da média da classe. $O$ mercado de trabalho tem sido rigoroso também em matéria de conduta. Não basta dominar os conhecimentos da sua profissão. Você precisa gostar do que faz. E fazer tudo com carinho, zelo, perseverança e comprometimento. Se você trabalhar como empregado, os seus supervisores estarão de olho no seu modo de encarar suas tarefas. Se você trabalhar por conta própria, os seus clientes esperam competência, atenção, cordialidade e demonstração de que você faz o seu serviço com prazer. O mundo do futuro estará cada vez mais atento às condutas e aos hábitos dos profissionais. (PASTORE, 2005)

As mudanças na base produtiva, conquanto tenham como condições para se efetivar um novo tipo de trabalhador, não exigiram, de fato, uma mudança paradigmática para o todo o conjunto de trabalhadores. Ainda assim, as proposições subjacentes ao modelo toyotista têm sido apropriadas como discurso em torno das novas competências, da empregabilidade e da formação continuada. Esse discurso ganha força à medida que aumenta o desemprego entre os jovens, o que resulta também numa procura cada vez mais acentuada por certificados e diplomas que elevem a qualificação e o nível de escolaridade dos trabalhadores, impulsionando o crescimento do mercado educacional. 


\section{Trabalhonecessário}

Issn: 1808 - 799X

ano 14, número $24-2016$

Entretanto, ao contrário do que apregoa a teoria do capital humano, a elevação do nível de escolaridade não se traduziu em menores taxas de desemprego. Segundo Pochmann (2008), se, em 1995, apenas 37,7\% dos desempregados possuíam o Ensino Básico completo, em 2004 a massa de desempregados com oito anos de estudo passou a 60,2 \%. Neste mesmo período, o desemprego entre aqueles que possuem nível universitário subiu de 98 para 247 mil, um número quase três vezes maior. O que esses números demonstram não é apenas um aumento do desemprego nas faixas de escolaridade maior; mais do que isso, revelam que, a despeito da elevação da escolaridade da população em geral, o desemprego continua atingindo os mesmos segmentos de classe, o que contradiz o discurso que associa maior escolaridade com maiores possibilidades de ascensão social.

$\mathrm{Na}$ verdade, podemos constatar hoje que o capital continua dispondo de um imenso exército de reserva, mas agora com nível de qualificação bem acima do exigido pelas características da maioria dos postos de trabalhos que vêm sendo criados, o que põe contesta a apologia ao novo perfil profissional de trabalhador polivalente e com as múltiplas competências demandadas pela nova base técnica da produção. Como bem resume Paranhos:

Embora estes requisitos profissionais representem as exigências de um núcleo de ocupações superiores e estáveis que decai progressivamente, 0 avanço tecnológico não implica necessariamente a maior complexidade dos postos de trabalho, pelo contrário, para imensa maioria dos empregos criados nas últimas décadas, a qualificação não se coloca como problema. Contudo, as empresas elevam cada vez mais os critérios de seleção para a contratação mesmo para o desempenho de atividades simples e rotineiras, tornando o padrão de acumulação flexível a base da demanda pela elevação da escolaridade e da qualificação dos trabalhadores. A carência de mão-de-obra qualificada para o trabalho complexo aparece muito mais como uma construção social e ideológica, ou seja, como estratégia de conformação e adaptação dos indivíduos à sociabilidade neoliberal, do que uma necessidade real da produção. (PARANHOS, 2010) 


\section{Trabalhonecessário}

Issn: 1808 - 799X

ano 14 , número $24-2016$

Longe de ser uma estratégia eficaz para a inclusão social e promoção do emprego e da vida digna para a juventude brasileira, as políticas focais de qualificação profissional, emprego e renda têm se limitado a equacionar déficits educacionais, numa perspectiva compensatória, oferecer uma qualificação profissional estreita e de qualidade duvidosa e tentar criar uma cultura de participação sempre restrita aos contextos locais e a demandas particularistas. $O$ horizonte que está colocado é o de adequação ao modelo econômico vigente, em que a garantia do emprego é substituída pela promessa de empregabilidade. Novas e antigas noções ideológicas ajudam a cimentar a ideia de que cabe aos jovens, no seu papel de "protagonista" ou de "ator estratégico do desenvolvimento", encontrar alternativas criativas para sua inserção produtiva seja através da ampliação do seu capital social, do empreededorismo, do cooperativismo ou simplesmente investindo nas competências que o mercado valoriza.

$\mathrm{Na}$ verdade, não havendo condições de oferecer perspectivas de inserção no mercado de trabalho, o que se busca é dar à juventude, alguma expectativa, mesmo sem garantia de acesso ao mercado formal. No limite, espera-se evitar que os jovens se envolvam em situações de risco social, o que, em última instância, implicaria o aumento dos índices de violência e uma maior desagregação do tecido social.

\section{Considerações finais}

Em que pesem as críticas da avaliação final feita pela OIT (relatório trabalho decente e Juventude), a Política Nacional de Juventude está em consonância com os compromissos assumidos por foros nacionais e internacionais, entre os quais se destaca a Agenda Hemisférica de Trabalho Decente (AHTD). Esta define como objetivo melhorar a formação e a inserção dos jovens no mercado de trabalho e, como meta, reduzir à metade a proporção de jovens que não estudam e não trabalham em um prazo de 10 anos. $\mathrm{Na}$ perspectiva adotada pela Política Nacional de Juventude, garantir oportunidades e 


\section{Trabalhonecessário}

Issn: 1808 - 799X

ano 14, número $24-2016$

direitos significa "ofertar meios para a aquisição de capacidades e para sua utilização, e de serviços que atendam às diferentes necessidades dos jovens de ambos os sexos". Ofertar e melhorar parecem palavras adequadas à noção de direito que emerge desses documentos: o direito a uma cidadania restrita que não garante a universalização do ensino de qualidade e o pleno emprego, mas oferece como prêmio de consolação políticas compensatórias e focais e a promessa da empregabilidade.

Entretanto, é preciso reconhecerque a Política Nacional de Juventude representa uma conquista e um avanço bastante significativos na disputa pela ampliação e consolidação de políticas públicas dirigidas à juventude. Ainda que as formulações e propósitos das ações e programas carreguem marcas da influência dos organismos internacionais e de outros agentes políticos e econômicos, deve-se ressaltar que o estabelecimento do marco representado pela Política Nacional da Juventude também é fruto da luta política de segmentos organizados da sociedade. As diferentes concepções ideológicas, programáticas e políticas que buscam orientar as políticas públicas voltadas para os jovens estarão permanentemente em disputa com resultados práticos que refletem e refletirão, em maior ou menor medida, a condensação da correlação de forças dentro do Estado (POULANTZAS, 1977). Nesse sentido, a Secretaria Nacional de Juventude (SNJ) e o Conselho Nacional de Juventude (CONJUVE) materializaram, no plano institucional e político, espaços de disputa e busca por legitimação, continuidade e consolidação de políticas de juventude que também se fizeram presentes no governo Dilma, garantindo a permanência do financiamento e da participação da sociedade civil na proposição das políticas voltadas aos jovens. Convergindo para esse processo, a realização das Conferências Nacionais da Juventude (que teve sua última edição em 2015) e a aprovação do Estatuto da Juventude, em 2013, apontam para consolidação de políticas de Estado voltadas à população jovem, que, malgrado às flutuações de governos, não negligencia as demandas da juventude brasileira.

Contudo, passados dez anos da instituição da Política Nacional de Juventude, é preciso admitir que ainda nos movemos em um terreno acidentado e 


\section{Trabalhonecessário}

Issn: 1808 - 799X

ano 14 , número $24-2016$

movediço, e o percurso não está livre de retrocessos, especialmente se consideramos os impactos da crise econômica e política que recaem sobre 0 governo Dilma. Nesse contexto, entidades da sociedade civil, intelectuais e movimentos sociais têm se mobilizado para impedir que possíveis medidas de ajuste e austeridade fiscal venham comprometer conquistas na área social. Em resposta à reforma ministerial, que em 2015 extinguiu a Secretaria-Geral da Presidência, a qual a SNJ encontrava-se vinculada e a transferiu juntamente com a CONJUVE, para o recém criado Ministério das Mulheres, da Igualdade Racial e dos Direitos Humanos, 175 organizações da sociedade civil, universidades e movimentos sociais assinaram um manifesto demonstrando preocupação com o "não-lugar" da secretaria na reforma e com as dificuldades que passaria a ter o CONJUVE no acompanhamento da formulação de políticas no novo ministério.

Com o afastamento provisório da presidenta e a subida ao poder do interino governo Temer, o que era preocupação candente com o lugar institucional da SNJ e do CONJUVE tornou-se uma ameaça real à continuidade das políticas públicas de juventude. O CONJUVE, que após a aprovação do impeachment na Câmara dos Deputados organizou um ato e emitiu nota pública manifestando-se de forma contrária ao impeachment da presidenta Dilma, assumiu pubicamente e de forma contundente o seu descontentamento com a extinção do Ministério ao qual se vinculava o SNJ. O segmento do conselho que representa a sociedade civil e que corresponde a 2/3 das cadeiras elaborou uma nota pública em 16 de maio de 2016 que não foi publicada pela área de comunicação que administra a página da internet "juventude.gov.br/", sob a alegação de tratar-se de "conteúdo indevido". O conteúdo divulgado em dois sites de jornalismo alternativo, "brasileiros.com.br" e "ocafezinho.com" deixa clara a insatisfação desse segmento do conselho que repudia a exclusão do Ministério das Mulheres, da Igualdade Racial, da Juventude e dos Direitos Humanos e do Ministério da Cultura. A nota é explícita quanto às expectativas nada otimistas para a política social e quanto à exclusão material e simbólica de segmentos minoritários da sociedade da participação e beneficiamento das políticas sociais. A nota é encerrada com o 


\section{Trabalhonecessário}

Issn: 1808 - 799X

ano 14, número $24-2016$

comprometimento do CONJUVE na denúncia do golpe em espaços relacionados a políticas públicas de juventude.

Não restam dúvidas de que vivemos o momento mais delicado na história recente do nosso País. A democracia, sempre conquistada à custa de lutas e vidas de sujeitos e grupos comprometidos com a mudança social, amadurece e se fortalece quando segmentos historicamente excluídos da sociedade não só se engajam e participam da vida pública, mas também são reconhecidos pelo Estado nas suas demandas e necessidades próprias. A juventude, especialmente a que se encontra hoje em situação de maior vulnerabilidade social, não pode sofrer com o revés social promovido por grupos políticos e econômicos a pretexto de sanar uma crise cujas raízes encontram-se em problemas de ordem cíclica do modo de produção capitalista, na sua fase mais atual.

Se é verdade que vivemos hoje uma nova onda de conservadorismo no Brasil, também é verdade que vivenciamos, desde as jornadas de junho, um novo cenário no qual os jovens, mais uma vez, se colocam como protagonistas, não como sujeitos econômicos, mas como sujeitos políticos, ainda que sob certas condições históricas, contextuais ou locais. O movimento de ocupação de escolas em São Paulo e no Rio de Janeiro certamente é a expressão de tais condicionantes e condições, mas não deixam de refletir anseios, dramas e formas de reação, que identificam, inspiram e fermentam a juventude na busca por sua afirmação objetiva e subjetiva, individual e coletiva, social e política. Enquanto houver jovens lutando, haverá esperança.

\section{REFERÊNCIAS}

BRASILEIROS.COM.BR. Conselho Nacional de Juventude não reconhece governo Temer. Disponível em http://brasileiros.com.br/4YueD. Acesso em 16/06/2016.

FRIGOTTO, Gaudêncio. O Brasil e a política econômico-social: entre o medo e a esperança. Observatório Social de América Latina, Buenos Aires, n. 14, p. 951004. Maio/Ago. 2004. 


\section{Trabalhonecessário}

Issn: 1808 - 799X

ano 14, número $24-2016$

FRIGOTTO, Gaudêncio; CIAVATTA, Maria e RAMOS, Marise. A Política de Educação Profissional no Governo Lula: Um Percurso Histórico Controvertido. Educação e Sociedade. Campinas, vol. 26, n. 92, Especial -. p. 1087-1113. Out/ 2005.

INSTITUTO CIDADANIA. Quem somos? Disponível em: http://institutocidadania.org.br/. Acesso em 16/06/2016

IPEA. Juventude e Políticas Sociais no Brasil. Brasília: 2009.

KUENZER, Acácia. A Educação Profissional nos anos 2000: A dimensão subordinada das políticas de inclusão. Revista Educação e Sociedade. Campinas, vol.27, n.96. Especial - p. 877-910. Out/2006.

OCAFEZINHO.COM. Conselho Nacional de Juventude não reconhece governo Temer. Disponível em http://www.ocafezinho.com/2016/05/16/conselhonacional-de-juventude-nao-reconhece-governo-golpista-de-temer/. Acesso em 16/06/2016.

OIT. Trabalho Decente e Juventude no Brasil. Brasília: 2009.

PARANHOS, Michelle Pinto. A política educacional para a formação dos trabalhadores e a especificidade do projeto capitalista brasileiro: o ideário Educacional em função da (des)qualificação do trabalho. Boletim Técnico do Senac. Rio de Janeiro, v. 36, n.2. Maio/Ago. 2010.

PASTORE, José. O emprego do futuro. Revista Onda Jovem. Instituto Votorantim. Ano I - Número 2 - Julho. 2005.

POCHMANN, Márcio. O emprego no desenvolvimento da nação. São Paulo: Boitempo, 2008.

POCHMANN, Márcio. A Batalha pelo Primeiro Emprego: As Perspectivas e a Situação Atual do Jovem no Mercado de Trabalho. São Paulo: Publisher Brasil,. v. 1.. 2000

POCHMANN, Márcio. Educação e trabalho: como desenvolver uma relação virtuosa? Educação e Sociedade, Campinas, v.25, n.87, p.383-399, maio/agosto 2004.

POULANTZAS, Nicos. Poder Político e Classes Sociais. São Paulo. Martins Fontes. 1977.

RAMONET, I. O pensamento único e os regimes globalitários. In: FIORI, J. L.; LOURENÇO, M. S.; NORONHA, J. C. Globalização: o fato e o mito. Rio de Janeiro: EDUERJ, 1998. 
Issn: 1808 - 799X

ano 14, número $24-2016$

SILVA, Enid Rocha Andrade da. ANDRADE, Carla Coelho de. A Política Nacional de Juventude: avanços e dificuldades. IN: CASTRO, Jorge Abraão de. AQUINO, Lusen Maria C. de. ANDRADE, Carla Coelho de. (org). Juventude e políticas sociais no Brasil. IPEA. BRASIL, 2009.

SILVA, Vini Rabassa da; SILVA, Roselani Sodré da. Política Nacional de Juventude: trajetória e desafios. Caderno CRH, v. 24, n. 63, p. 663-678, 2011.

SPOSITO, Marília Pontes. Algumas reflexões e muitas indagações sobre as relações entre juventude e escola no Brasil. In: Abramo, H. W.; Branco, P. P. M. (Orgs.).Retratos da juventude brasileira. São Paulo: Fundação Perseu Abramo; Instituto Cidadania; p. 175-214. 2005

UNESCO. Políticas Públicas De/Para/Com as Juventudes. Brasília, UNESCO, 2004.

Recebido: 24 de junho de 2016 Aprovado: 04 de agosto de 2016 